\title{
Covid-19 Epidemic Dynamic Including Barriers of Circulation
}

\author{
Sebastião Gomes ${ }^{1}$ and Igor Monteiro ${ }^{1}$ \\ ${ }^{1}$ Federal University of Rio Grande
}

May 6, 2020

\begin{abstract}
In this article we analyze the evolutionary dynamics of the novel coronavirus epidemic (covid-19) using observed data from several cities and places in the world. We have used a SIR-type (Susceptible, Infectious and Recovered) model improved with some adaptions in order to increase its predictive skills, i.e., we have included the circulation restriction effect and considered a phenomenon we have called adherence zone, generating the Modified SIR model (ModSIR). Comparing the results produced with ModSIR with real observations obtained for several places in the world we have found that ModSIR presented good predictive skill, as long as combined with good enough parametric identification. At the end of this article we present a study in which we simulated an epidemic in a hypothetical city of 211000 inhabitants. We have extracted several useful conclusions by analyzing some epidemic scenarios in which we evaluate epidemic control by adopting the circulation restriction as a control variable.
\end{abstract}

\section{Hosted file}

scpgomes.pdf available at https://authorea.com/users/317341/articles/447447-covid-19epidemic-dynamic-including-barriers-of-circulation
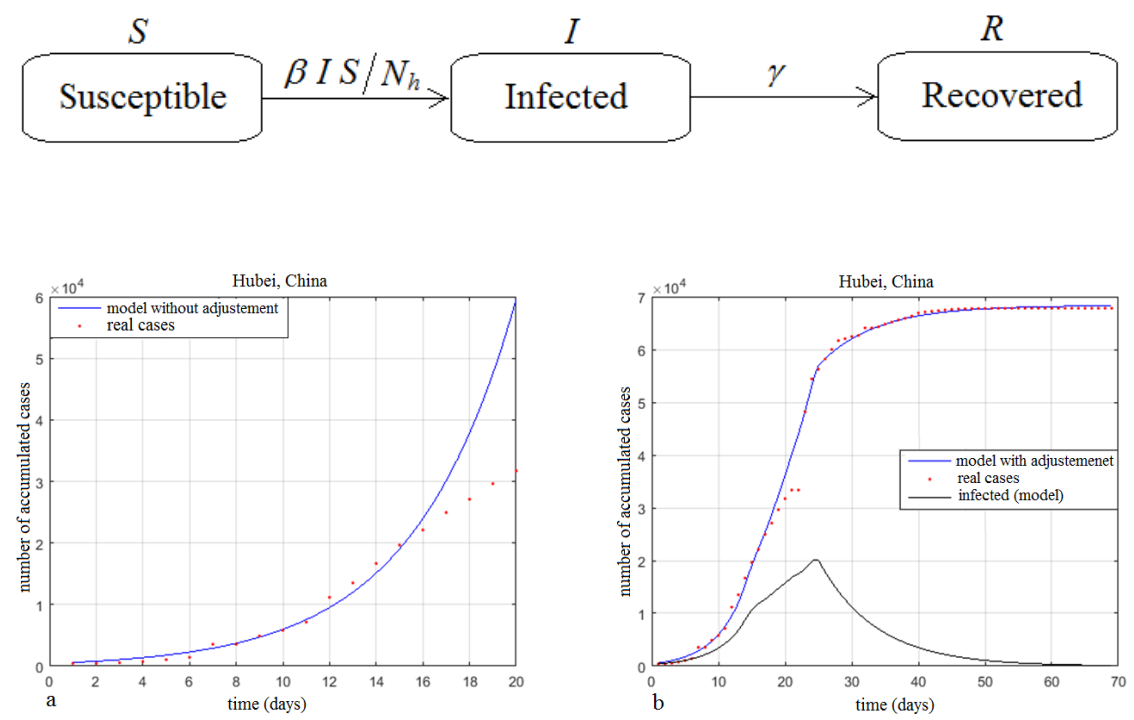

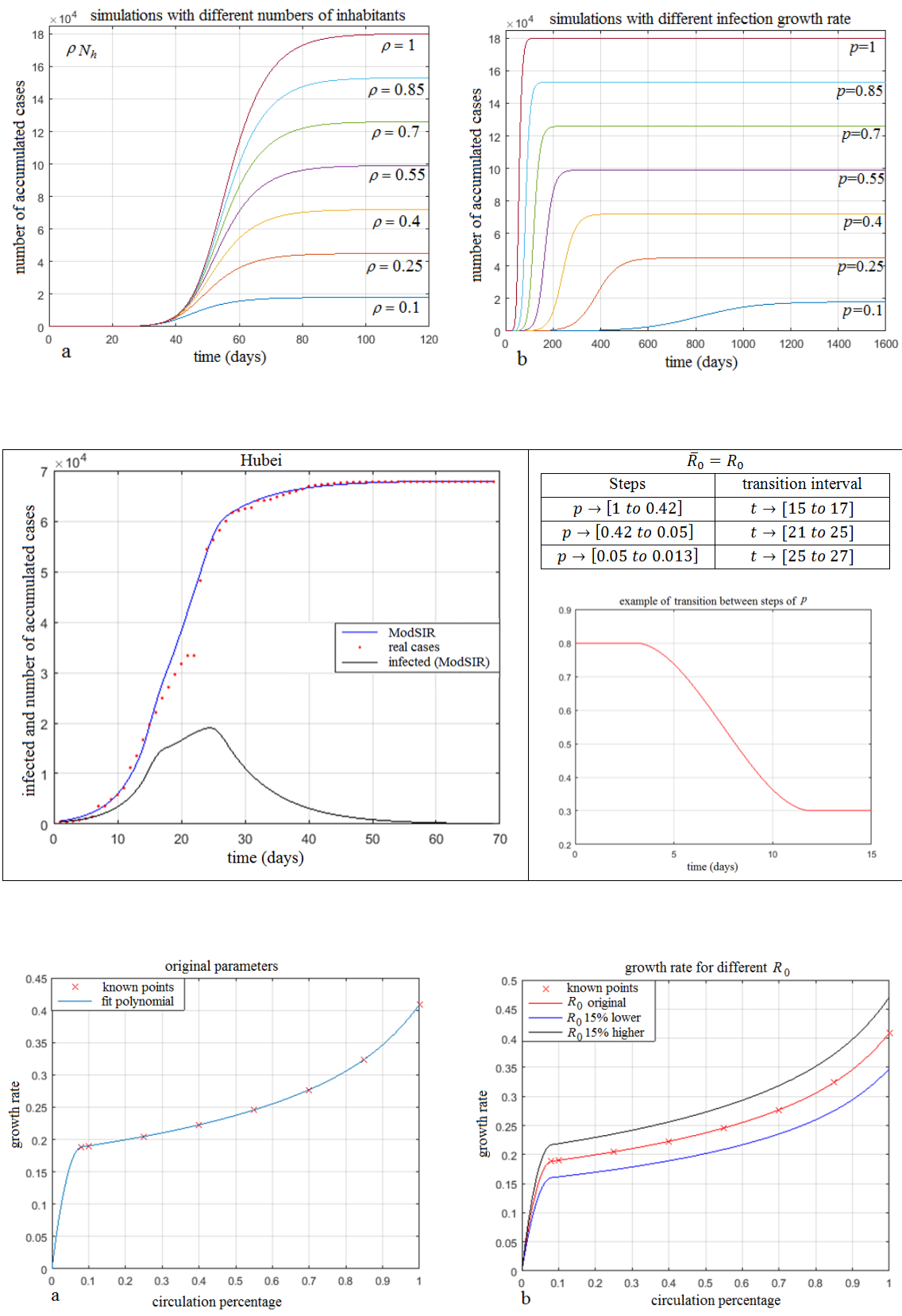

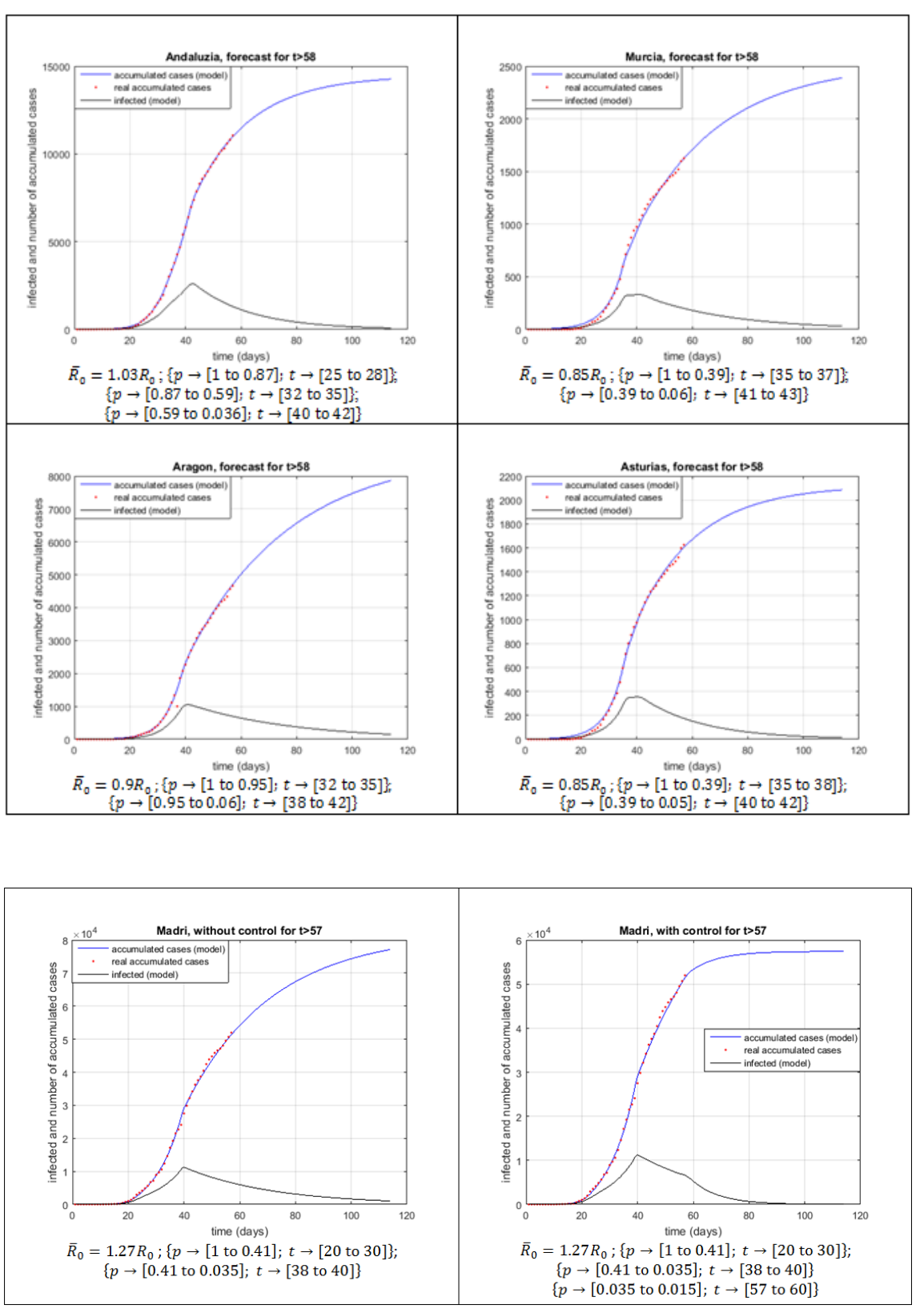

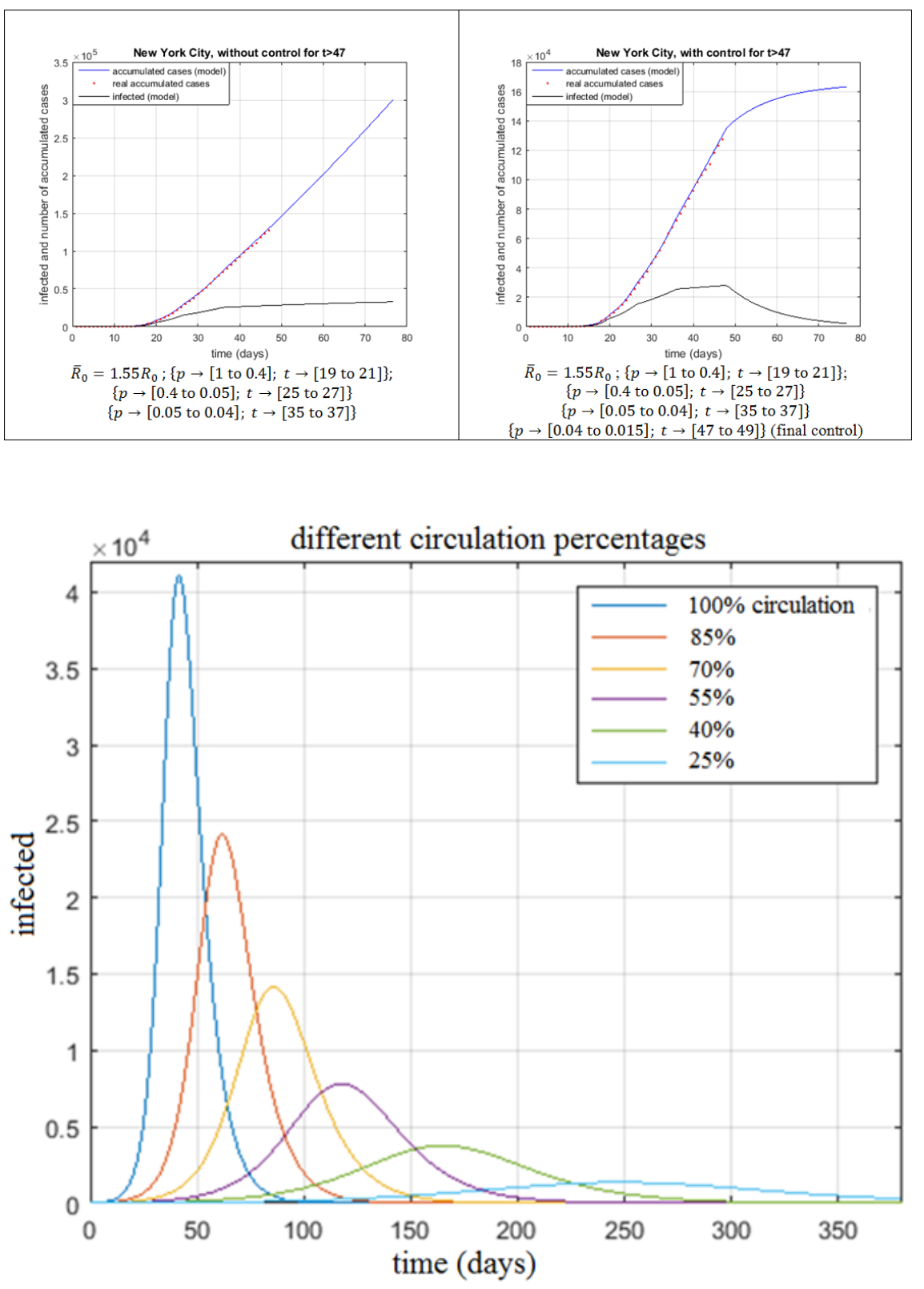

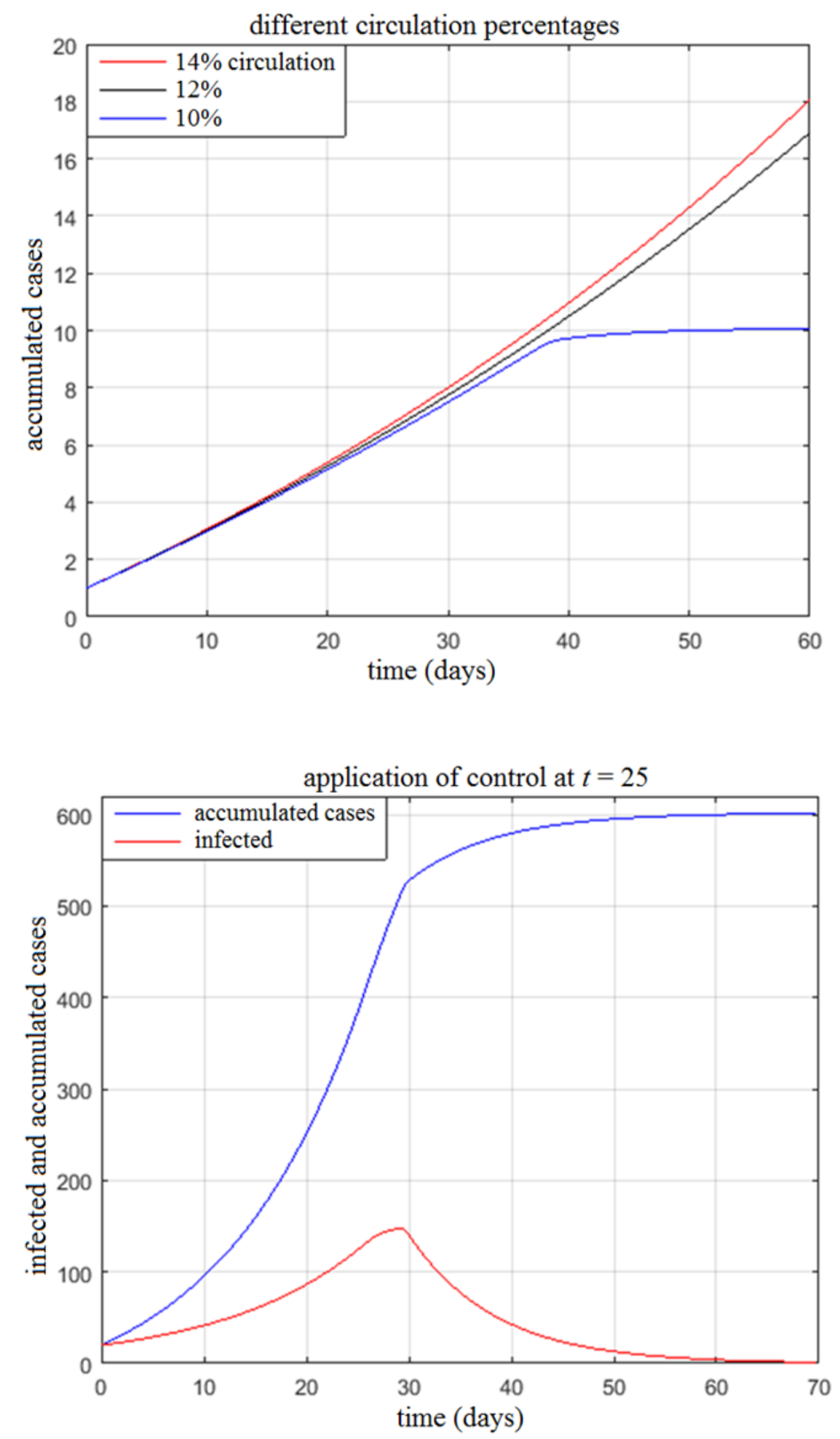

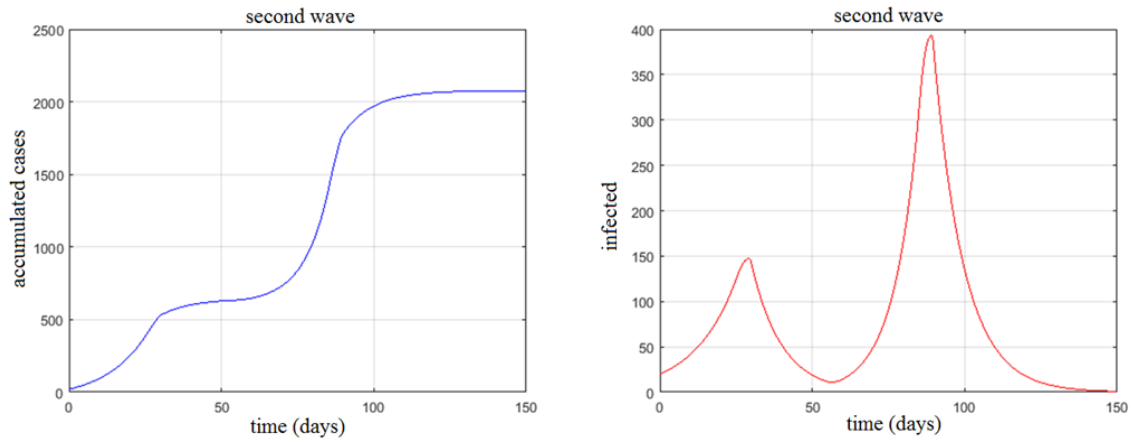